American Journal of Applied Sciences 1 (4): 284-294, 2004

ISSN 1546-9239

(C) Science Publications, 2004

\title{
Real Time Hybrid Controller Implementation for Switched Reluctance Motor Drive
}

\author{
S. Paramasivam and R. Arumugam \\ Department of Electrical and Electronics Engineering, \\ Anna University, India
}

\begin{abstract}
This study presents the real time hybrid controller implementation for a Switched Reluctance motor Drive. The developed hybrid control law consists of Proportional Integral (PI) controller at steady state, PI-type fuzzy logic controller (FLC) at transient state and a simple logic controller between steady and transient states to achieve desired performance at various operating conditions under soft chopping operation. The importance of hybrid controlling is highlighted by comparing the performance of various control approaches, including PI control, PI-type fuzzy logic control, PD type fuzzy control for speed control of SRM motor drives. The complete control algorithm is demonstrated by intensive experimental results. It is shown that the presented hybrid controller for SRM drive is with fast tracking capability, less steady state error and robust to load disturbance. The complete speed control scheme of the SRM drive incorporating the hybrid control is experimentally implemented and validated using a high speed digital signal processor board TMS320F2812 for a prototype 1.2- kW SRM.
\end{abstract}

Key words: FLC, Switched Reluctance Motor (SRM), PI, PD, Speed Control, Hybrid Control, Digital Signal Processor (TMS320F2812)

\section{INTRODUCTION}

Switched Reluctance Motor (SRM) drives have been used for many years in applications, where simplicity of construction was primary important. An SRM is a rotating electric motor, where both stator and rotor have salient poles. The stator winding comprises a set of coils, each of which is wound on one pole. The rotor is made from laminated in order to minimize the eddy current losses. The rotor tries to get to a position of minimum reluctance by aligning itself with the stator magnetic field when the stator winding are excited ${ }^{[1,2]}$. Due to its attractive features of high power density, high efficiency and low maintenance cost, SRM is widely used in high performance servo applications, such as aerospace, industrial and robotic ${ }^{[1-10]}$. SRM cannot be run directly from the supply. It can be run only when the motor is integrated with a power converter, controller and rotor position sensor. Many researchers have been reported on the performance simulation of SRM with experimental validation for different control strategies such a feedback linearization control, variable structure control, fuzzy logic control and four quadrant operation of SRM ${ }^{[11-16]}$. None of these have focused exclusively on fast tracking capability, less steady state error and robust to load disturbance during steady state and transient conditions. Hence, it is necessary to design a hybrid digital controller for SRM to get the optimum performance in the presence of the parameters variations and load disturbances. This study proposes a hybrid controller where in discrete PI and PI type fuzzy logic control algorithms are combined to get the desired performance of SRM. This controller employs only with the speed error and changes in speed error and produces an equivalent control term. The designed hybrid controller improves system performance in transient and steady state.

SRM description: The SRM has a salient pole stator with concentrated windings and also a salient pole rotor with no magnets or coils. The basic principle of torque production is discussed in ${ }^{[1,2]}$. In this study, a prototype 3 phase, 6/4 pole SRM is considered and is shown in Fig. 1. The prototype motor parameters are given in Appendix 1.

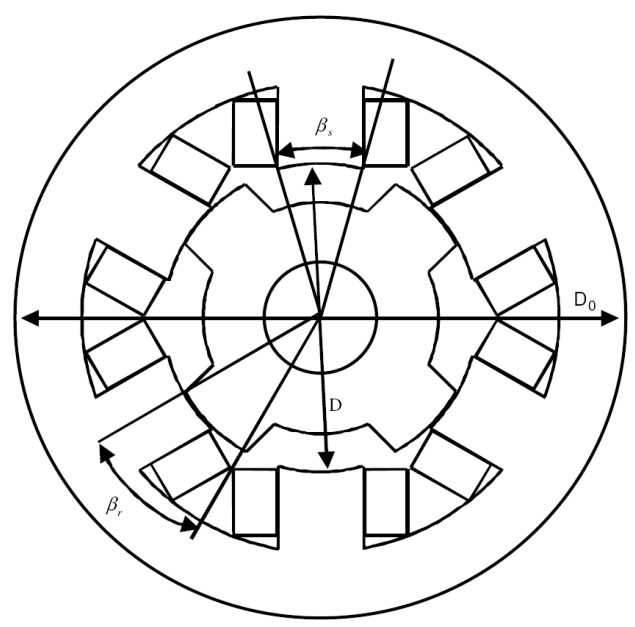

Fig. 1: 6/4 Pole Prototype SRM 


\section{Appendix 1 Motor Parameters}

Power: $1.2 \mathrm{KW}$

Current: $16 \mathrm{~A}$

Stator outer diameter: $162 \mathrm{~mm}$

Stator core length: $90 \mathrm{~mm}$

Stator inner diameter: $80 \mathrm{~mm}$

Shaft diameter: $25 \mathrm{~mm}$

No of poles in the stator: 6

No of turns/pole: 75

Cross section of the conductor: $1.7 \mathrm{sq}-\mathrm{mm}$

Stator pole arc: $29 \mathrm{deg}$

Stator pole height: $20 \mathrm{~mm}$

No of poles in the rotor: 4

Rotor pole arc: $32 \mathrm{deg}$

Rotor Pole height: $15 \mathrm{~mm}$

All the three phases are assumed to be identical. Hence, all the equations are described with respect to the generic phase $(\mathrm{j}=1,2$ and 3$)$. Due to the symmetrical location of the poles, mutual inductances between the phases are neglected. The discrete mathematical model of the SRM is a set of controlled difference equations obtained by the use of standard SRM theory. The differential equations that describe the dynamics of SRM are approximated as follows:

$$
\begin{aligned}
& \mathrm{v}_{\mathrm{jn}} \mathrm{i}_{\mathrm{jn}} \mathrm{R}_{\mathrm{j}}+\mathrm{L}_{\mathrm{jn}} \frac{\left[\mathrm{i}_{\mathrm{jn}}-\mathrm{i}_{\mathrm{jn}-1}\right]}{\Delta \mathrm{t}}+\mathrm{i}_{\mathrm{jn}} \frac{\left[\mathrm{L}_{\mathrm{jn}}-\mathrm{L}_{\mathrm{jn}-1}\right]}{\Delta \mathrm{t}} \\
& \mathrm{J} \frac{\omega_{\mathrm{n}}-\omega_{\mathrm{n}-1}}{\Delta \mathrm{t}}+\mathrm{B} \omega_{\mathrm{n}}=\sum_{\mathrm{j}=1}^{3 .} \mathrm{T}_{\mathrm{jn}}\left(\theta_{\mathrm{n}}, \mathrm{i}_{\mathrm{n}}\right)-\mathrm{T}_{\mathrm{Ln}} \\
& \omega_{\mathrm{n}} \frac{\theta_{\mathrm{n}}-\theta_{\mathrm{n}-1}}{\Delta \mathrm{t}} \\
& \mathrm{T}_{\mathrm{jn}}\left(\theta_{\mathrm{n}}, \mathrm{i}_{\mathrm{n}}\right)=\left[\frac{\Delta \mathrm{W}_{\mathrm{jc}}}{\Delta \theta}\right]_{\mathrm{i}=\mathrm{cont}} \\
& \mathrm{W}_{\mathrm{jcn}}=\Psi_{\mathrm{jn}} \mathrm{i}_{\mathrm{jn}} \Delta \mathrm{t}+\mathrm{W}_{\mathrm{jcn}-1} \\
& \Delta \theta=\theta_{\mathrm{n}}-\theta_{\mathrm{n}-1}
\end{aligned}
$$

Where:

$$
\begin{array}{ll}
\mathrm{V}_{\mathrm{jn}} & =\text { Voltage across the } \mathrm{j}^{\text {th }} \text { phase at nth instant } \\
\mathrm{i}_{\mathrm{jn}} & =\text { Current of the } \mathrm{j}^{\text {th }} \text { phase at nth instant } \\
\mathrm{i}_{\mathrm{jn}-1} & =\text { Current of } \mathrm{j}^{\text {th }} \text { phase at }(\mathrm{n}-1)^{\text {th }} \text { instant } \\
\mathrm{R}_{\mathrm{j}} & =\text { Resistance of the } \mathrm{j}^{\text {th }} \text { phase } \\
\mathrm{L}_{\mathrm{jn}} & =\text { Inductance of the } \mathrm{j}^{\text {th }} \text { phase at nth instant } \\
\mathrm{L}_{\mathrm{jn}-1} & =\text { Inductance of the } \mathrm{j}^{\text {th }} \text { phase at }(\mathrm{n}-1)^{\text {th }} \\
& \text { instant } \\
\psi_{\mathrm{jn}} & =\text { Flux linkage of the } \mathrm{j}^{\text {th }} \text { phase at nth instant } \\
\Delta \mathrm{t} & =\text { Sample time } \\
\mathrm{J} & =\text { Moment of inertia }
\end{array}
$$

B $=$ Viscous friction coefficient of the motorload system

$\theta_{\mathrm{n}} \quad=$ Rotor position at nth instant

$\theta_{\mathrm{n}-1}=$ Rotor position at $(\mathrm{n}-1)^{\text {th }}$ instant

$\omega_{\mathrm{n}} \quad=$ Actual speed of motor at nth instant

$\omega_{n-1}=$ Actual speed of the motor at $(n-1)^{\text {th }}$ instant

$\mathrm{T}_{\mathrm{jn}}\left(\theta_{\mathrm{n}}, \mathrm{i}_{\mathrm{n}}\right)=$ Electromagnetic torque produced by $\mathrm{j}^{\text {th }}$ phase at nth instant

$\mathrm{T}_{\mathrm{Ln}}=$ Load torque applied to the shaft of the motor at nth instant

$\Delta_{\mathrm{Wjc}} \quad=$ Change in co energy of $\mathrm{j}^{\text {th }}$ phase

$\mathrm{W}_{\text {cjn }} \quad=$ Co energy of $\mathrm{j}^{\text {th }}$ phase at nth instant

$\mathrm{W}_{\text {cjn-1 }}=$ Co energy of $\mathrm{j}^{\text {th }}$ phase at $(\mathrm{n}-1)^{\text {th }}$ instant

$\mathrm{j}=$ Number of phases

From equation (1), it is understood that the emotional voltage of each phase is proportional to the angular velocity and the rate of change of inductance with respect to rotor position ${ }^{[1,2]}$. According to the equation (4), electromagnetic torque (T) produced by the SRM phase is directly proportional to the rate of change in co energy. It is understood that the motor creates positive torque in the direction of increasing flux linkage and negative torque in the direction of decreasing flux linkage. Hence it is required to choose the proper rotor position to get the proper control of the SRM. In order to achieve better control and speed response in all regions, it is required to design a hybrid controller.

Fuzzy logic controller implementation: The basic block diagram of a PI type FLC for SRM speed control is shown in Fig. 2. It is known that FLC consists of fuzzification process, knowledge base and defuzzification process $^{[17]}$. Figure 2 shows the block diagram of PI type FLC and PD type FLC for the SRM control. In the case of a PI-type FLC, the actual value of the controller output is obtained by the following equation (7):

$\mathrm{u}(\mathrm{k})=\mathrm{u}(\mathrm{k}-1)+\Delta \mathrm{u}(\mathrm{k})$

Where:

$\mathrm{u}(\mathrm{k}) \quad=$ Controller output

$\mathrm{u}(\mathrm{k}-1)=(\mathrm{k}-1)^{\text {th }}$ instants controller output

$\Delta \mathrm{u}(\mathrm{k})=$ Incremental change in controller output

In the above equation (7), an accumulation of controller output takes place outside the FLC and is not directly reflected in the rules themselves. The block diagram for PI-type FLC can be used for PD type FLC, if the output of the FLC is $\mathrm{u}(\mathrm{k})$ not $\Delta \mathrm{u}(\mathrm{k})$ and also there is no accumulation of the controller output. In both cases, speed error $\left(\mathrm{e}_{\mathrm{N}}\right)$ and change of speed error $\left(\Delta_{\mathrm{eN}}\right)$ are the input variables and $\left(\Delta \mathrm{u}_{N}\right)$ is the output variable. Figure 3a-c shows membership functions of input variables $\left(e_{N}\right.$ and $\left.\Delta_{\mathrm{eN}}\right)$ and output variable $\left(\Delta \mathrm{u}_{\mathrm{N}}\right)$, wherein conventional triangular shapes and with $50 \%$ overlapping is selected. 


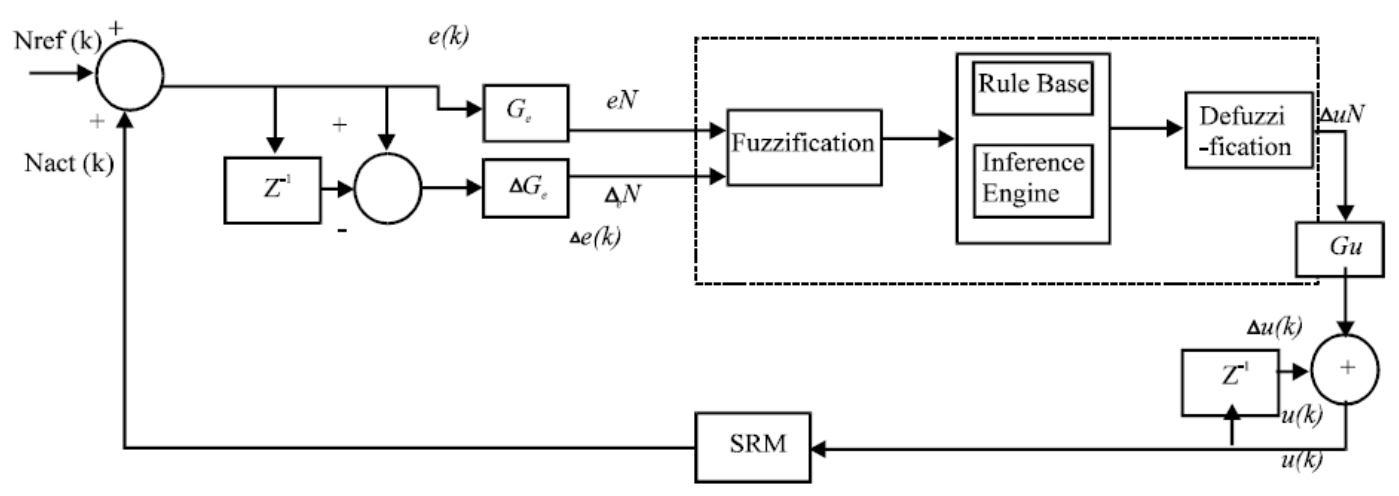

Fig. 2: FLC for SRM Speed Control
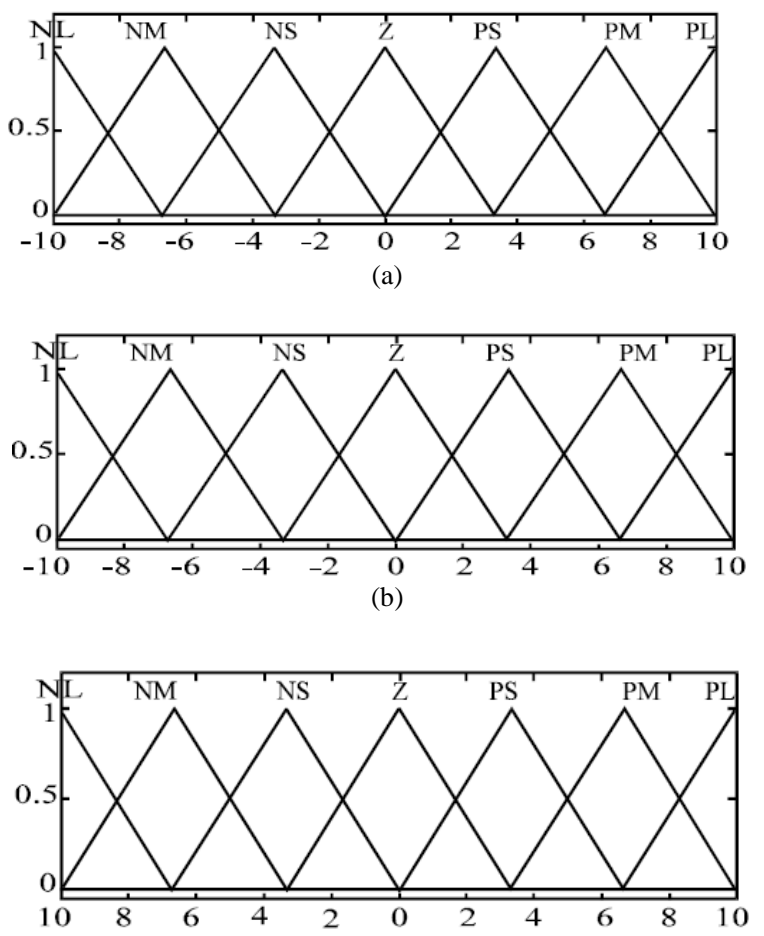

(c)

Fig. 3: Illustration of Membership Function for Input and Output Variables

As shown in Fig. 3, each membership function is assigned with seven fuzzy sets, which are negative Large (NL), negative medium (NM), negative small (NS), zero (Z), positive small (PS), positive medium (PM), and positive large (PL). The rule bases for PItype and PD type FLC is formed by experience gained during practical experiments on SRM in open loop operation. Table 1 and 2 show the linguistic rule bases for PI-type and PD-type fuzzy logic controllers respectively. The most important difference between these two linguistic rules is that the selection of switching boundary at which the sign of the rule change. In the case of PI-type FLC, the switching boundary is diagonal and for PD-type FLC is a horizontal line along speed " $\mathrm{e}_{\mathrm{N}}$ " equals zero.
Table 1: Rule Base for PI-Type Fuzzy Logic Controller

\begin{tabular}{|c|c|c|c|c|c|c|c|}
\hline $\begin{array}{l}\Delta \mathrm{e}_{\mathrm{N}} \\
\mathrm{e}_{\mathrm{N}}\end{array}$ & NL & NM & NS & $\mathrm{Z}$ & PS & $\mathrm{PM}$ & PL \\
\hline$\overline{\mathrm{NL}}$ & NL & NL & NL & NL & NL & NM & $\mathrm{Z}$ \\
\hline NM & NL & NL & NL & NL & NM & Z & PS \\
\hline NS & NL & NL & NM & NM & Z & PS & PM \\
\hline Z & NL & NM & NS & Z & PS & PM & PL \\
\hline PS & NM & NS & Z & PS & PM & PL & PL \\
\hline PM & NS & Z & PS & PM & PL & PL & PL \\
\hline PL & Z & PS & PM & PL & PL & PL & PL \\
\hline
\end{tabular}

Table 2: Rule Base for PD-Type Fuzzy Logic Controller

\begin{tabular}{|c|c|c|c|c|c|c|c|}
\hline \multicolumn{7}{|l|}{$\mathrm{e}_{\mathrm{N}}$} & PL \\
\hline $\mathrm{NL}$ & NL & NL & NL & NL & NM & NS & NS \\
\hline NM & NL & NL & NL & NM & NS & NS & NS \\
\hline NS & NL & NL & $\mathrm{NM}$ & NS & NS & NS & NS \\
\hline Z & NS & NS & NS & $\mathrm{Z}$ & PS & PS & PS \\
\hline PS & PS & PS & PS & PS & PM & PL & PL \\
\hline PM & PS & PS & PS & PM & PL & PL & PL \\
\hline PL & PS & PS & PM & PL & PL & PL & PL \\
\hline \multirow{3}{*}{\multicolumn{2}{|c|}{$\begin{array}{l}\text { PI } \\
\text { Control }\end{array}$}} & \multirow{3}{*}{\multicolumn{2}{|c|}{$\begin{array}{l}\text { PI type } \\
\text { fuzzy } \\
\text { Control }\end{array}$}} & \multirow{2}{*}{\multicolumn{2}{|c|}{ PD type }} & \multirow{3}{*}{\multicolumn{2}{|c|}{$\begin{array}{l}\text { Hybrid } \\
\text { Control }\end{array}$}} \\
\hline & & & & & & & \\
\hline & & & & \multicolumn{2}{|c|}{ Control } & & \\
\hline \multicolumn{2}{|c|}{$\mathrm{Kp}=1.663$} & \multicolumn{2}{|c|}{$\mathrm{Ge}=1 / 1750$} & $\mathrm{Ge}=1$ & & \multicolumn{2}{|c|}{$\mathrm{Kp}=3.0$} \\
\hline \multirow[t]{4}{*}{$\mathrm{Ki}=0.008$} & & \multicolumn{2}{|c|}{$\Delta \mathrm{Ge}=\frac{1}{3}$} & \multicolumn{2}{|c|}{$\Delta \mathrm{Ge}=3$} & \multicolumn{2}{|c|}{$\mathrm{Ki}=0.42$} \\
\hline & & \multirow{3}{*}{\multicolumn{2}{|c|}{$\Delta \mathrm{Gu}=3$}} & \multirow{3}{*}{\multicolumn{2}{|c|}{$\mathrm{Gu}=9$}} & \multicolumn{2}{|c|}{$\mathrm{Ge}=1 / 1750$} \\
\hline & & & & & & \multicolumn{2}{|c|}{$\Delta \mathrm{Ge}=\frac{1}{3}$} \\
\hline & & & & & & \multicolumn{2}{|c|}{$\Delta \mathrm{Gu}=\frac{1}{3}$} \\
\hline
\end{tabular}

The operation of PI type FLC can be explained with the following example. From the Fig.4 (a and b), it is understood that the error $\left(\mathrm{e}_{\mathrm{N}}\right)$ is 1.68 and the change in error $\left(\Delta \mathrm{e}_{\mathrm{N}}\right)$ is 4 . For the considered example, there are four rules are invoked as shown in Table 1.

By Table 1 (bolded linguistic variable), these four rules and inference results are:

Rule 1 if $\mathrm{e}_{\mathrm{N}}=\mathrm{Z}$ and $\Delta \mathrm{e}_{\mathrm{N}}=\mathrm{PS}$ then $\Delta_{\mathrm{u} 1}=\mathrm{PS}$;

Rule 2 if $\mathrm{e}_{\mathrm{N}}=\mathrm{Z}$ and $\Delta \mathrm{e}_{\mathrm{N}}=\mathrm{PM}$ then $\Delta_{\mathrm{u} 2}=\mathrm{PM}$;

Rule 3 if $\mathrm{e}_{\mathrm{N}}=\mathrm{PS}$ and $\Delta \mathrm{e}_{\mathrm{N}}=\mathrm{PS}$ then $\Delta_{\mathrm{u} 3}=\mathrm{PM}$;

Rule 4 if $\mathrm{e}_{\mathrm{N}}=\mathrm{PS}$ and $\Delta \mathrm{e}_{\mathrm{N}}=\mathrm{PM}$ then $\Delta_{\mathrm{u} 4}=\mathrm{PL}$; 


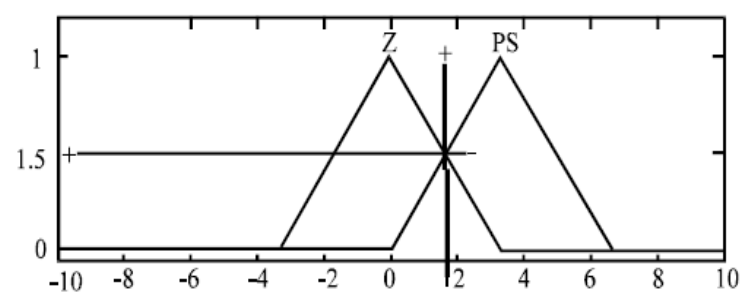

(a)

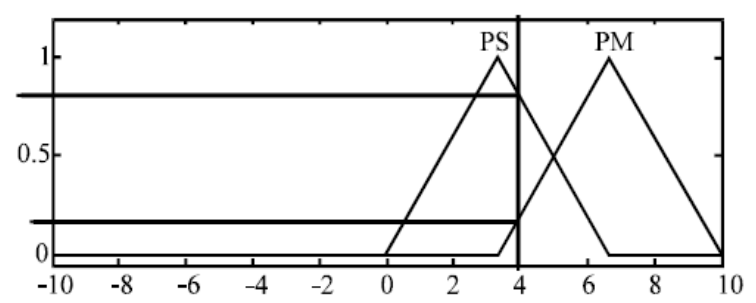

(b)

Fig. 4: Determination of Degree of Membership for Error and Change in Error

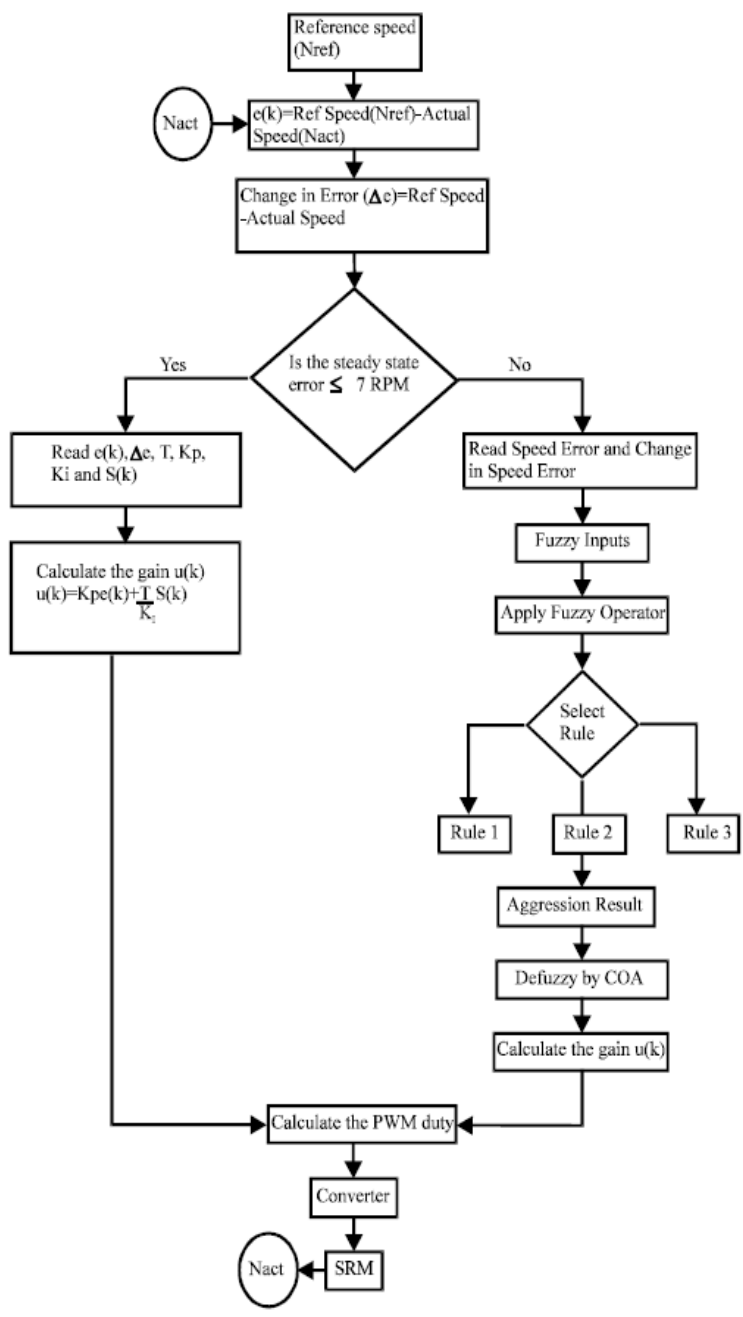

Fig. 5: Flow Chart for Hybrid Control Algorithm
The membership grade values corresponding to $\Delta \mathrm{u}_{\mathrm{N}}$ are obtained from a singleton membership function, $\Delta \mathrm{u}_{\mathrm{N}}$, as shown in Fig. 3. (c). Once the fuzzy inference results are obtained from the inference engine, the actual control output can be obtained from the defuzzification process to get the crisp output. In this research, the inferred fuzzy control action is converted to a crisp value, $\Delta \mathrm{u}$, through the commonly used Center Of Area (COA) method to obtain:

$$
\Delta \mathrm{u}=\frac{\sum_{\mathrm{N}=1}^{4} \Delta \mathrm{uN} \mu \mathrm{cN}}{\sum_{\mathrm{N}=1}^{4} \mu \mathrm{cN}}
$$

Where:

$\Delta \mathrm{u}=$ Grade value of $\Delta \mathrm{u}_{\mathrm{N}}$, which is obtained from the fuzzy inference results and membership function, $\Delta \mathrm{u}$ as shown in Fig. 3.c

$\mu \mathrm{cN}=$ Weighting factor, obtained by using Mamdani's minimum fuzzy implication rule

For an error $=1.68$ and $\mu[\mathrm{eN}] \varepsilon$ "Z" and "PS". The membership grade value for $\mu \mathrm{Z}[\mathrm{eN}=1.68]$ and $\mu \mathrm{PS}[\mathrm{eN}$ $=1.68$ ] are calculated by the simple triangular geometry and its equation (9) is given as:

$$
\mu_{\delta}(x)=\begin{array}{cc}
0 & x \leq a \\
\frac{x-a}{b-a} & a \leq x \leq b \\
\frac{c-x}{c-b} & b \leq x \leq c \\
0 & c \leq x
\end{array}
$$

Degree of membership for the considered error $\left(\mathrm{e}_{\mathrm{N}}\right)$ is $\mu \mathrm{Z}[\mathrm{eN}=1.5]=0.5$ and $\mu \mathrm{PS}[\mathrm{eN}=1.5]=0.5$. Similarly for change in error $\left(\Delta \mathrm{e}_{N}\right)=4, \mu\left[\Delta \mathrm{e}_{N}\right] \varepsilon$ "PS" and "PM". The membership grade value for $\mu \operatorname{PS}\left[\Delta \mathrm{e}_{\mathrm{N}}=4\right]$ and $\mu \mathrm{PM}\left[\Delta \mathrm{e}_{\mathrm{N}}=4\right]$ are calculated by the simple triangular geometry as explained above. Degree of membership for the change in error $\left(\Delta \mathrm{e}_{\mathrm{N}}\right)$ is $\mu \operatorname{PS}\left[\Delta \mathrm{e}_{\mathrm{N}}=4\right]=0.8001$ and $\mu \mathrm{PM}\left[\Delta \mathrm{e}_{\mathrm{N}}=4\right]=0.1999$. The details to obtain the weighting factor $\mu \mathrm{cN}, \mathrm{N}=1,2,3$ and 4 are obtained by Mamdani's minimum implication rule and as given below:

$$
\begin{aligned}
& \mu \mathrm{c}_{1}=\min \left\{\mu \mathrm{z}\left(\left(\mathrm{e}_{\mathrm{N}}\right)=1.68\right), \mu_{\mathrm{PS}}\left(\left(\Delta \mathrm{e}_{\mathrm{N}}\right)=4\right)\right\} \\
& =\min \{0.5,0.199\}=0.199 \\
& \mu \mathrm{c}_{2}=\min \left\{\mu \mathrm{z}\left(\left(\mathrm{e}_{\mathrm{N}}\right)=1.68\right), \mu_{\mathrm{PM}}\left(\left(\Delta \mathrm{e}_{\mathrm{N}}\right)=4\right)\right\} \\
& =\min \{0.5,0.199\}=0.199 \\
& \mu \mathrm{c}_{3}=\min \left\{\mu_{\mathrm{PS}}\left(\left(\mathrm{e}_{\mathrm{N}}\right)=1.68\right), \mu_{\mathrm{PM}}\left(\left(\Delta \mathrm{e}_{\mathrm{N}}\right)=4\right)\right\} \\
& =\min \{0.5,0.8001\}=0.5
\end{aligned}
$$




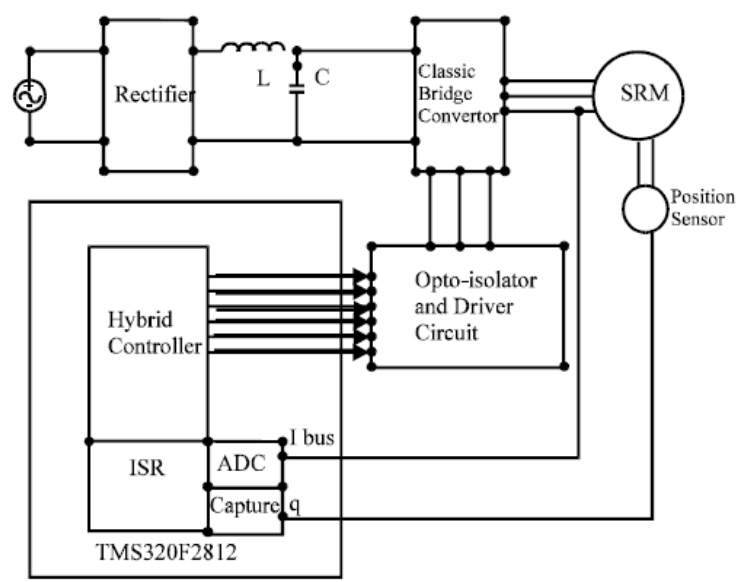

(a)

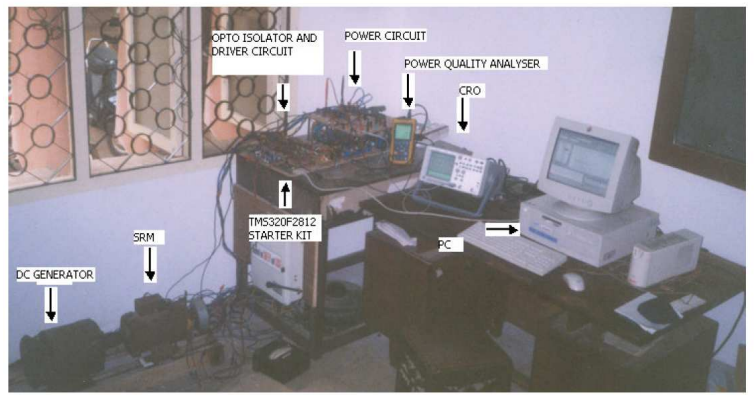

(b)

Fig. 6: (a) DSP based SRM Drive System and (b) Photograph of an Experimental System

$\mu \mathrm{c}_{4}=\min \left\{\mu_{\mathrm{PS}}\left(\left(\mathrm{e}_{\mathrm{N}}\right)=1.68\right), \mu_{\mathrm{PM}}\left(\left(\Delta \mathrm{e}_{\mathrm{N}}\right)=4\right)\right\}$

$=\min \{0.5,0.199\}=0.199$

$\Delta \mathrm{u}$ can be found as follows:

$\Delta \mathrm{u}=\frac{\Delta \mathrm{u} 1 \mu_{\mathrm{c} 1}+\Delta \mathrm{u} 2 \mu_{\mathrm{c} 2}+\Delta \mathrm{u} 3 \mu_{\mathrm{c} 3}+\Delta \mathrm{u} 4 \mu_{\mathrm{c} 4}}{\mu_{\mathrm{c} 1}+\mu_{\mathrm{c} 2}+\mu_{\mathrm{c} 3}+\mu_{\mathrm{c} 4}}=5.8836$

Hybrid controller implementation: In the previous section, the complete implementation of the FLC for SRM drive is explained. It is well known that FLC is robust to load disturbance or sudden change in reference speed, it has got a significant steady state error as compared with that for a conventional proportional integral controller ${ }^{[18]}$. Hence an implementation of a hybrid controller is necessary to overcome with the drawbacks existing in the FLC. Figure 5 shows the flow chart representation of the presented hybrid controller. As shown in Fig. 5, the hybrid controller consists of a combined effect of PI controller and PI-type fuzzy controller and a simple logical comparator, wherein a logical switching mechanism changes the control action form one controller to another controller based on the speed error value, thereby a high performance control action can be achieved under transient and steady state.

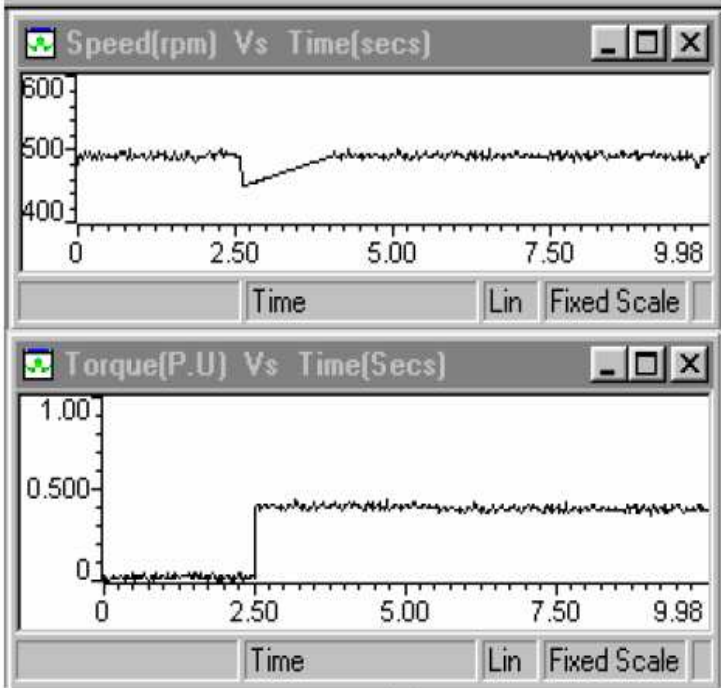

(a)

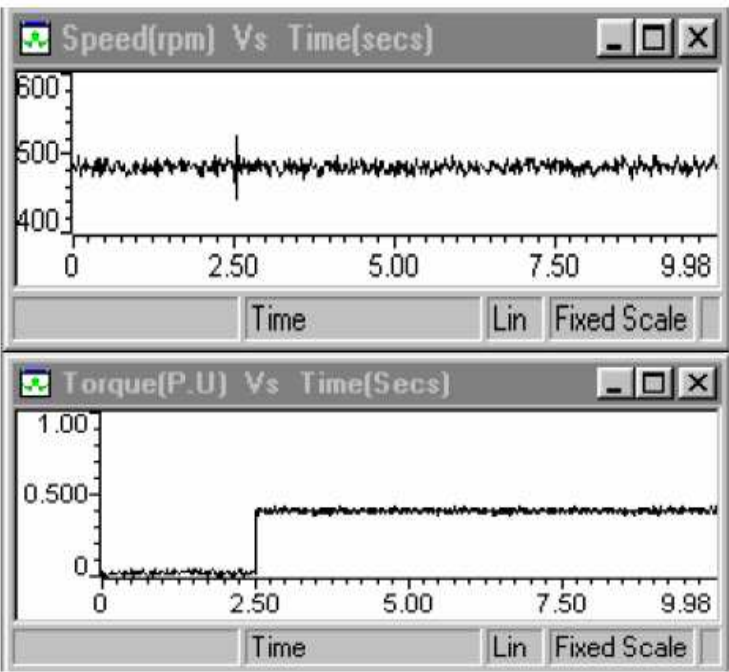

(b)

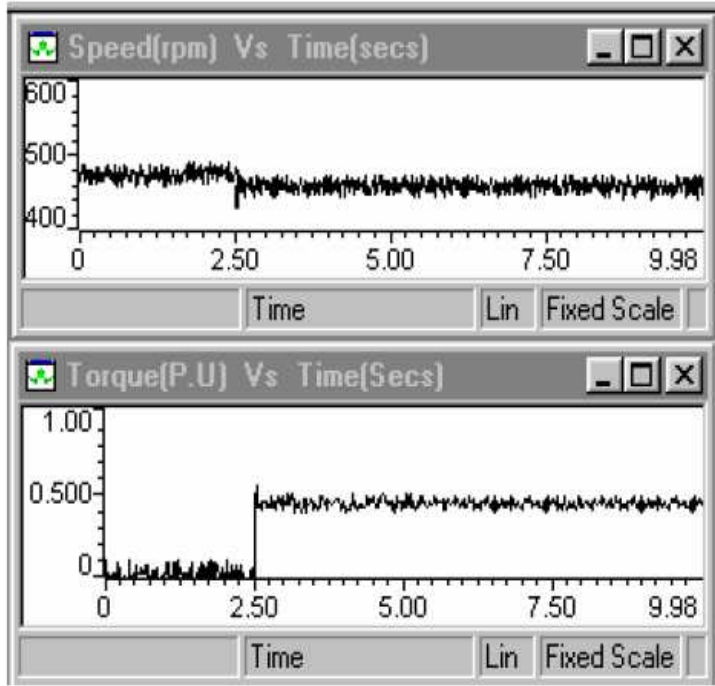

(c) 


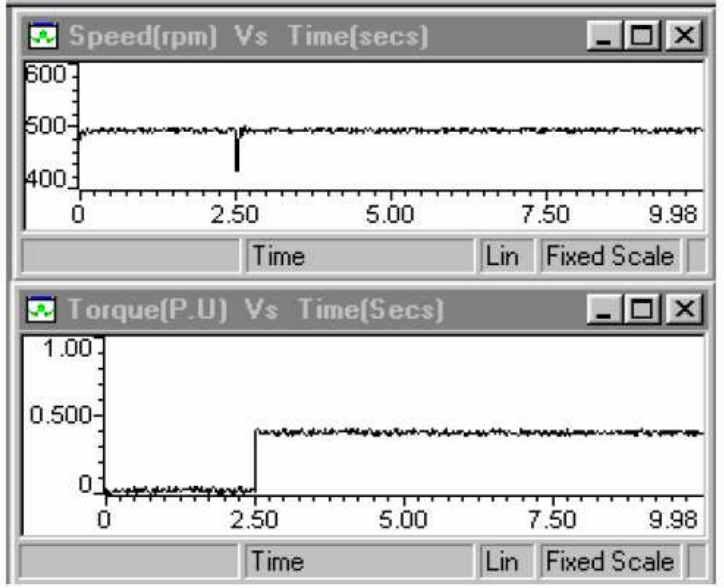

(d)

Fig. 7: Experimental Results, Speed (top), Torque (bottom), 0.4 p.u. Load, 480 rpm. (a) PI Control. (b) PI-Fuzzy Control. (c). PD type Fuzzy Control (d) Hybrid Control

Table 4: $\mathrm{N}_{\mathrm{RMSE}}$

\begin{tabular}{|c|c|c|c|c|}
\hline \multirow[b]{2}{*}{ Type of control } & \multicolumn{4}{|l|}{ RMSE } \\
\hline & $480 \mathrm{rpm}$ & $750 \mathrm{rpm}$ & 1350 & $1700 \mathrm{rpm}$ \\
\hline PI Control & 4.56 & 3.91 & 4.12 & 5.36 \\
\hline PI type Fuzzy control & 5.25 & 4.15 & 5.67 & 6.18 \\
\hline PD type Fuzzy control & 18.65 & 21.35 & 26.33 & 29.14 \\
\hline Hybrid control & 2.16 & 1.87 & 2.31 & 2.73 \\
\hline
\end{tabular}

The PI-controller takes decision during steady state to reduce the steady state error of the system and the PItype fuzzy logic controller takes decision during transient state to get a fast response and low overshoot when the absolute value of speed error is greater than 7 RPM. For the system presented in this study, the maximum value of $\mathrm{N}_{\mathrm{RMSE}}$ of PI-type fuzzy logic controller is 6.18 RPM, which is given Table 4. Therefore, the threshold value is selected as $7 \mathrm{rpm}$. This set value depends upon the PI-type fuzzy logic controller and the sampling frequency of ADC. Figure 7 through Fig. 10 shows the experimental results for the SRM drive using the hybrid controller and other controllers. As shown in Figs 7 to 10, for the case of steady state, the PI-controller dominates the control output to significantly reduce the steady state error of the system and the PI-type FLC contributes to the output to provide fast response and low overshoot when the absolute value of speed error is higher than 7 RPM. To emphasize the advantages of a proposed hybrid controller with other controllers, a controller of PI, PItype fuzzy logic control, PD-type fuzzy logic control is also implemented.

\section{RESULTS}

A DSP based SRM Drive system as shown in Fig. 6, which includes TMS320F2812 starter kit, classic bridge converter, rotor position sensor, current sensing circuit and 6/4 pole SRM was set up for obtaining the experimental results ${ }^{[1,2,19,20]}$. The complete photograph of an experimental system is given in Fig. 6. (b). In order to find the performance of different control algorithms, the following formula is used to find the $\mathrm{N}_{\text {RMSE }}$, wherein $(\mathrm{N}=100)$ samples are taken into consideration to find the $\mathrm{N}_{\mathrm{RMSE}}$ :

$\mathrm{N}_{\text {RMSE }}=\sqrt{\frac{\sum_{\mathrm{k}=1}^{\mathrm{N}}\left(\mathrm{N}_{\mathrm{ref}}-\mathrm{N}_{\mathrm{act}}(\mathrm{k})\right)^{2}}{\mathrm{~N}}}$

Where:

$\mathrm{N}_{\mathrm{RMSE}}=$ Speed Root Mean square error

$\mathrm{N}_{\text {ref }} \quad=$ Reference speed in rpm

$\mathrm{N}_{\mathrm{act}}=$ Actual speed in rpm

$\mathrm{N} \quad=$ No of samples

Figure 7 through Fig. 10 show the experimental results of the SRM drive at different operating conditions under soft chopping mode. Fig 11 shows the phase voltage and phase current at different reference speeds after application of load at $t=2.5$ secs in soft chopping mode. Figure 7 shows speed response to reference speed $=480 \mathrm{RPM}$ and $40 \%$ load is applied to the shaft of the motor at $t=2.5$ secs. From the results, it can be concluded the following.

PI controller is more suitable during steady state, however it is not robust to load disturbance or change in speed reference.

The combined effect of PI and PI type FLC (hybrid controller) is more suitable for both transient and steady state.

Similar results are obtained for other reference speeds as illustrated in Fig. 8-10, using reference speed 750 RPM, 1350rpm, and 1700rpm, respectively, as examples.

The controller parameters of PI, PI type fuzzy, PD type and hybrid control algorithms are obtained by conducting the real time experiments of SRM in an open loop control. The parameters of various controllers are shown in Table 3. Comparison results are obtained and presented in Table 4 for different control algorithms from the intensive experiments at different reference speeds, which shows the torque and speed ripples at steady state. As shown in Table 4, the presented hybrid controller has the smallest values of $\mathrm{N}_{\mathrm{RMSE}}$ for various reference speed values. From the experimental results, it is concluded that hybrid controller has smaller $\mathrm{N}_{\mathrm{RMSE}}$ and hence very low torque ripple. It can be concluded the following observations can be made from these experimental results and are explained. Figure 12 shows the experimental results of step response with 200 RPM. As shown in Fig. 12 (a), the tracking performance for conventional PI-control is not good enough due to parameter variations. 


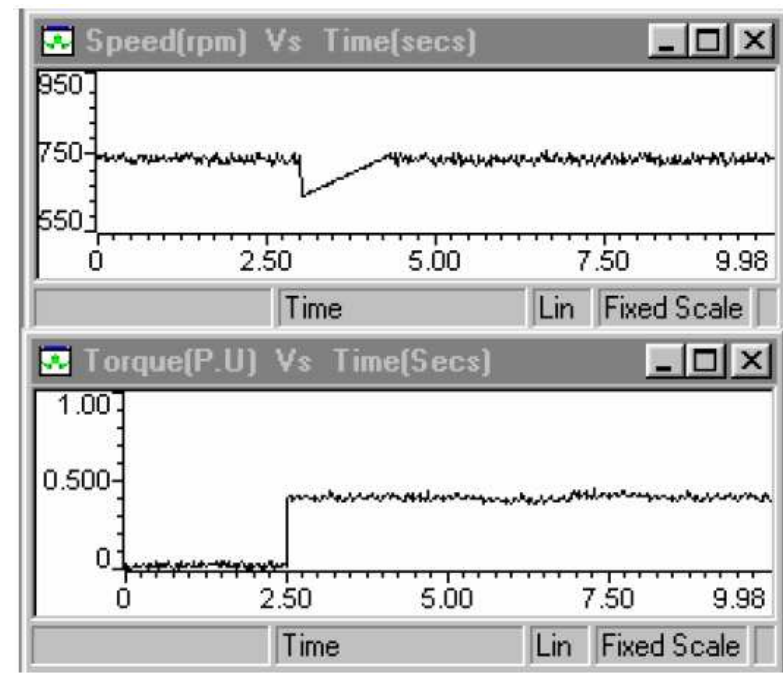

(a)

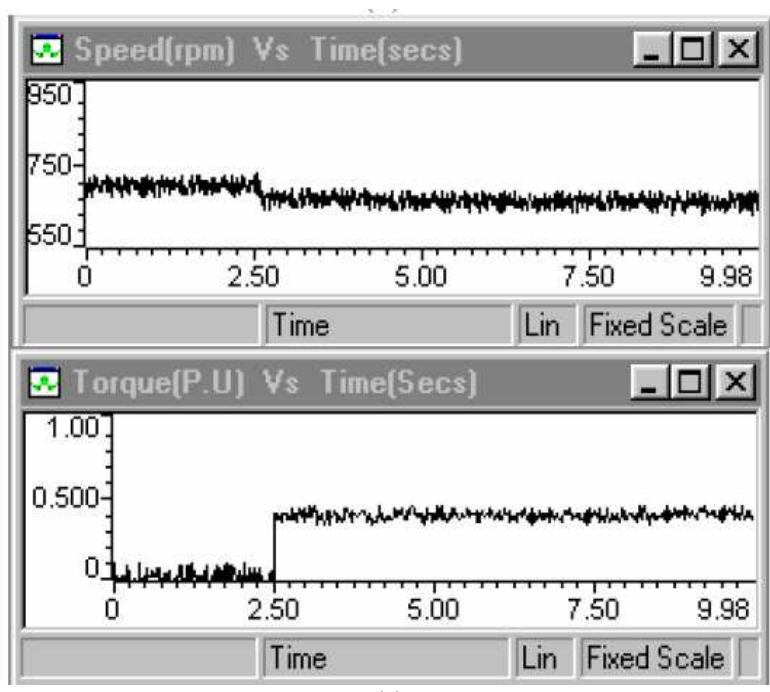

(c)
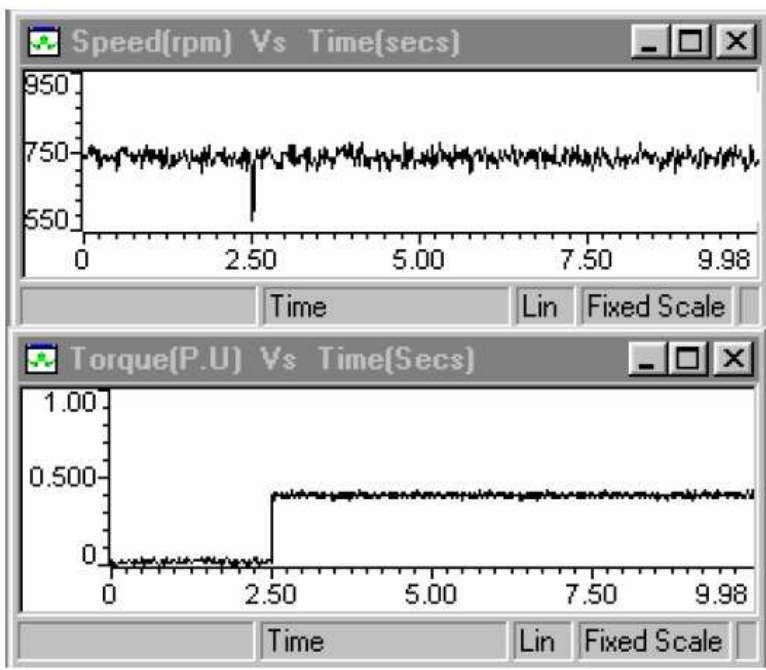

(b)
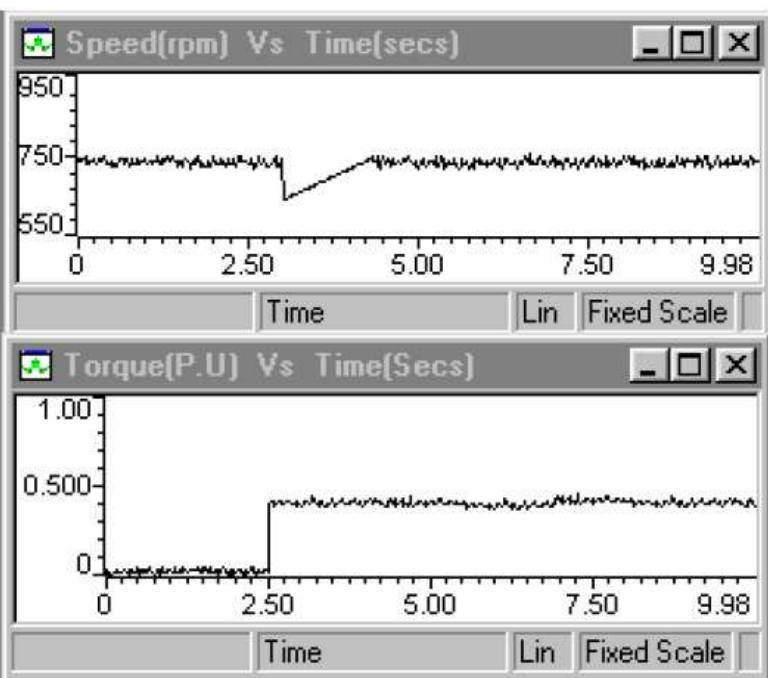

(d)

Fig. 8: Experimental Results, Speed (top), Torque (bottom), 0.4 p.u. Load, 750 RPM. (a) PI Control. (b) PI-Fuzzy Control. (c). PD type Fuzzy Control (d) Hybrid Control

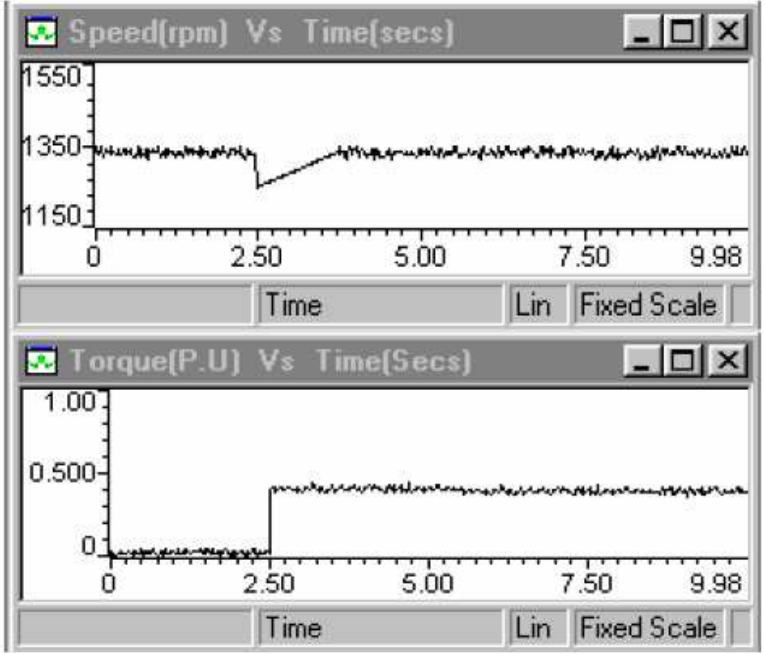

(a)

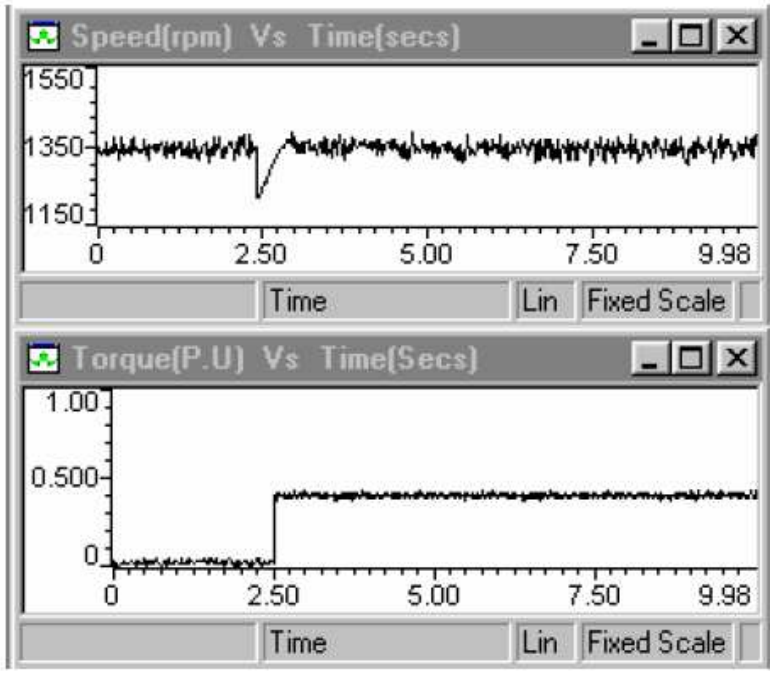

(b) 


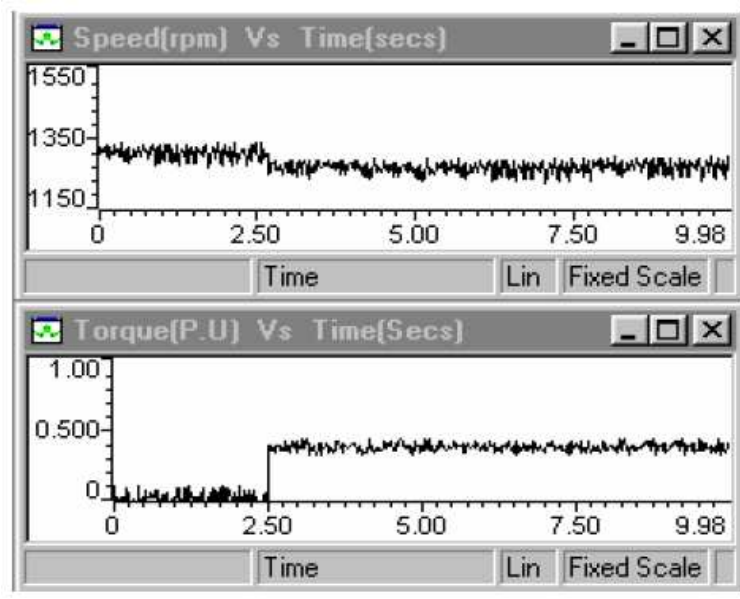

(c)

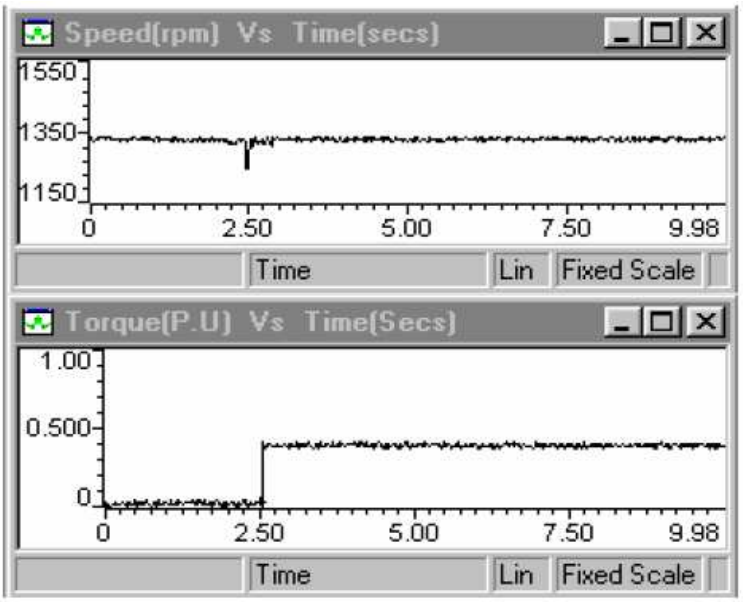

(d)

Fig. 9: Experimental Results Speed (top), Torque (bottom), 0.4 p.u. Load, 1350 rpm. (a) PI Control. (b) Fuzzy Control. (c). Hybrid Control

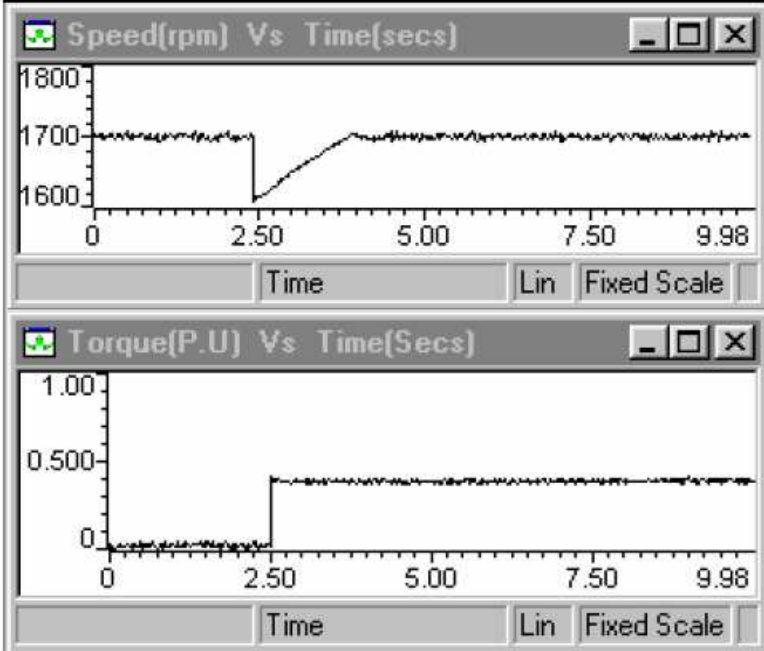

(a)

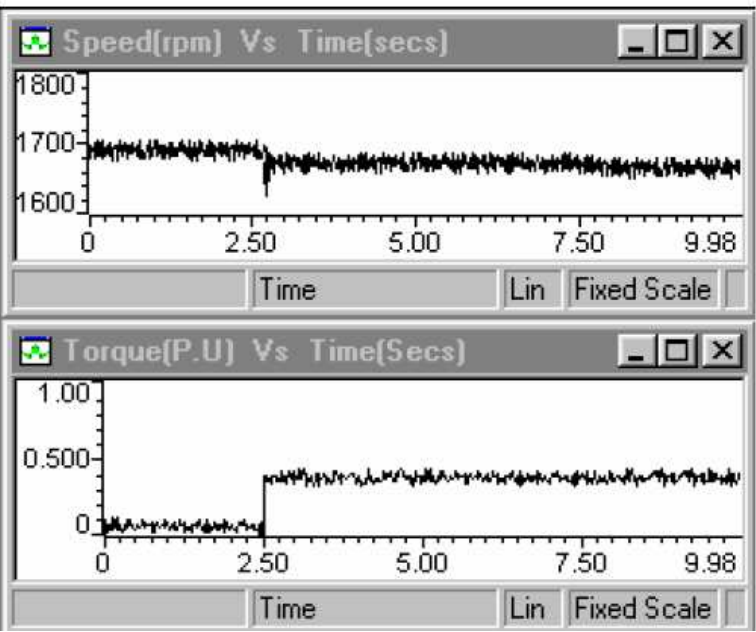

(c)

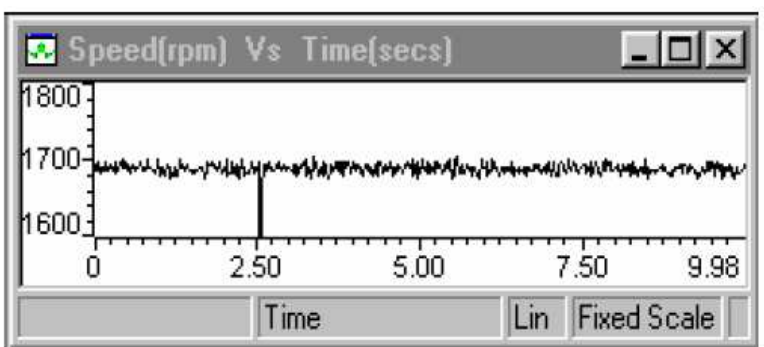

(b)

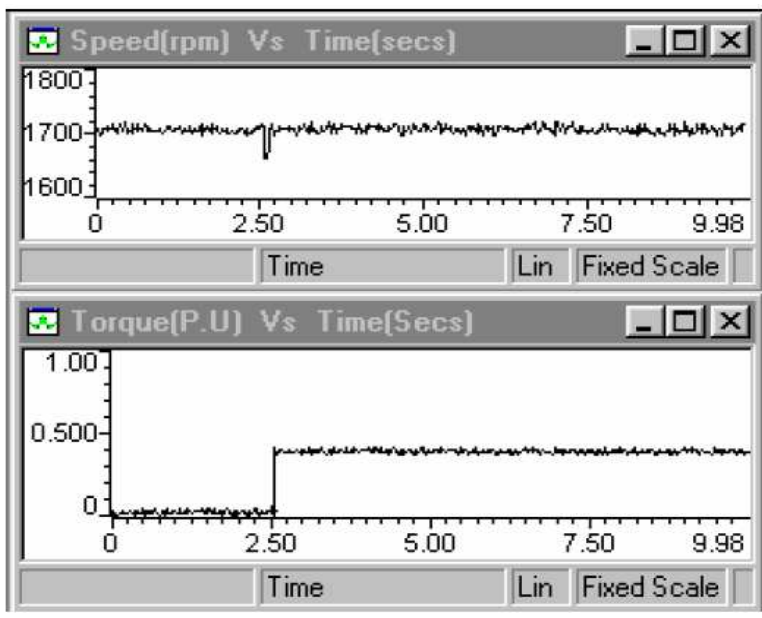

(d)

Fig. 10: Experimental Results, Speed (top), Torque (bottom), 0.4 p.u. Load, 1700 RPM (a) PI Control. (b) Fuzzy Control. (c). Hybrid Control 


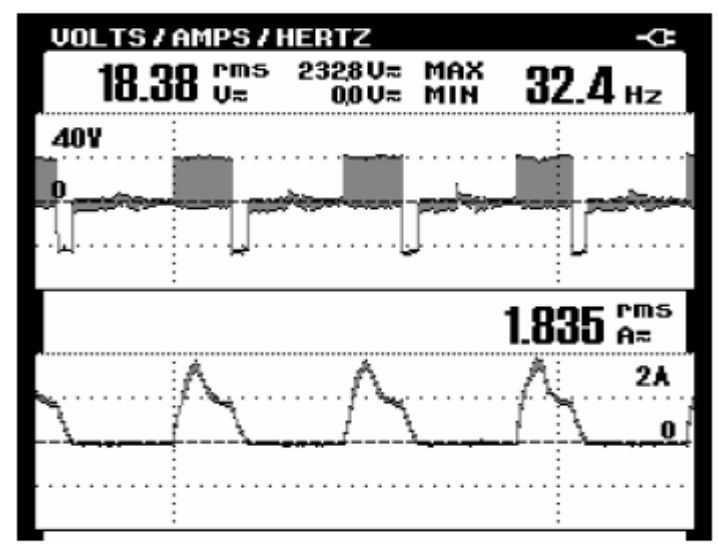

(a)

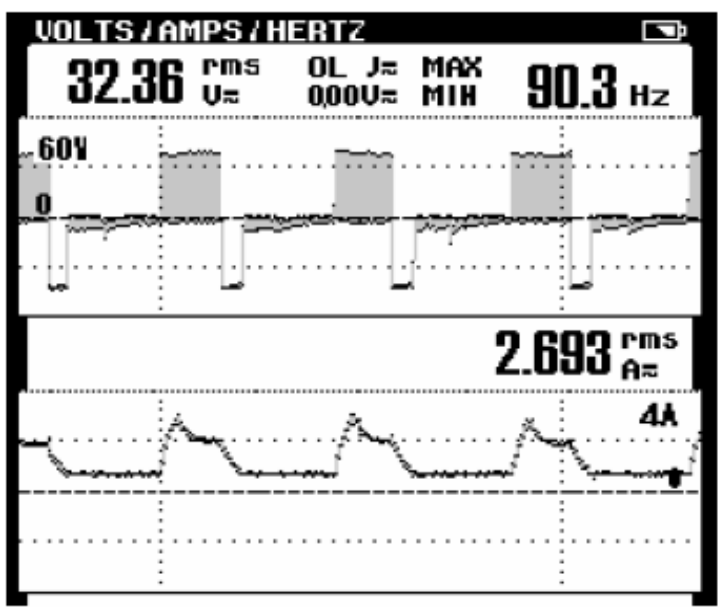

(c)

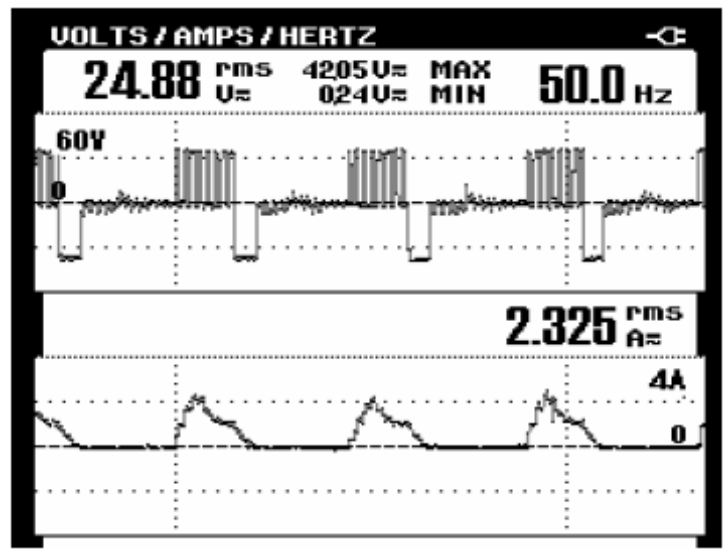

(b)

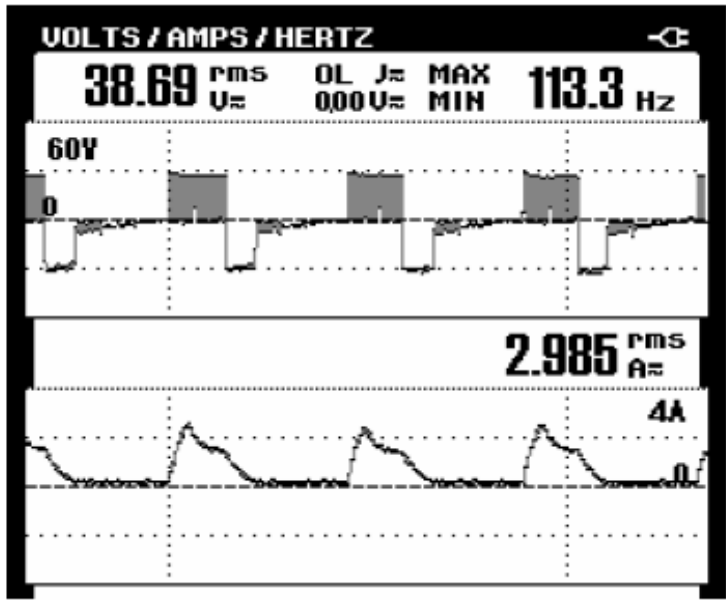

(d)

Fig. 11: Experimental Results, Voltage/phase (top), Current/phase (bottom), 0.4 p.u. Load (a) 480 RPM, (b) 920rpm and (c) 1690 RPM

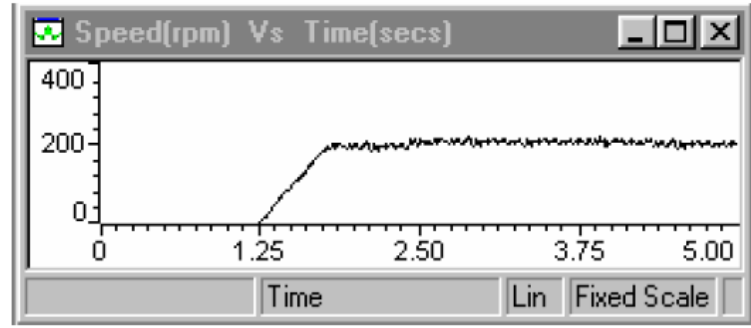

(a)

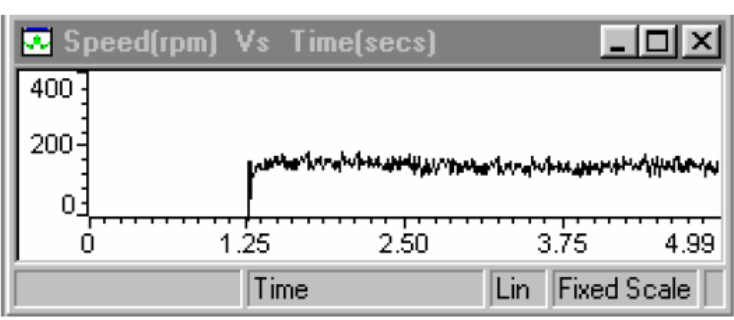

(c)

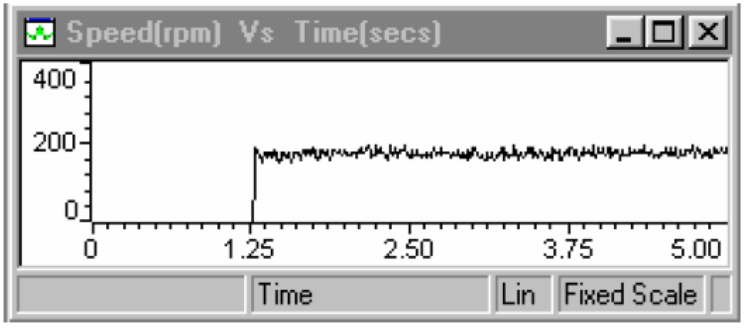

(b)

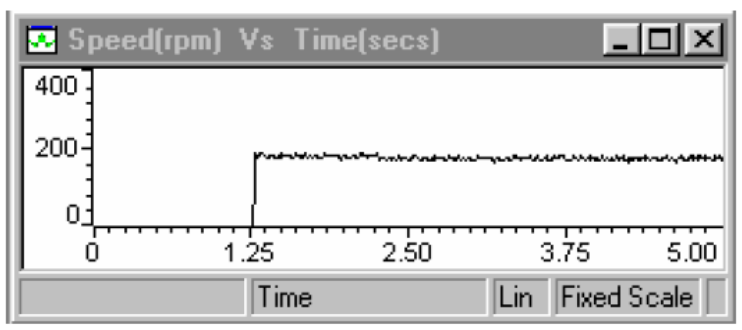

(d)

Fig. 12: Experimental Results; Step Response, 200 RPM. (a) PI Controller, (b) PI-type FLC., (c) PD-type FLC (d) Hybrid Control 
Table 5: Performance Comparison

\begin{tabular}{llll}
\hline Performance & Steady state error & Tracking performance & Robustness to load disturbance \\
\hline PI Control & Best & Poor & Good \\
PI Type Fuzzy control & Good & Best & Best \\
PD type fuzzy control & Very Poor & Very Poor & Very Poor \\
Hybrid control & Best & Best & Best \\
\hline
\end{tabular}

In contrast, the tracking performance of the controllers other than conventional PI type is satisfied even that the mechanical parameters vary. As shown in Fig. 12 (c) the steady state error for PD-type fuzzy control is still significant for not having an integral mechanism. Comparison results derived from the intensive experimental data can be summarized in Table 5, which shows that the presented hybrid controller is superior to the others regarding to the steady state error, tracking performance, and load disturbance rejection.

\section{CONCLUSION}

A major issue in the research was the fast tracking capability, less steady state error and robust to load disturbance of the speed control scheme of the SRM drive. The proposed hybrid controller reduces the steady state error as compared with PI-type Fuzzy Logic Controller (FLC), while keeping the merits of PItype FLC. Experimental results prove that the presented hybrid controller for a speed control of SRM drive provides fast tracking capability, less steady state error and robust to load disturbance. To demonstrate the ability of the presented scheme in actual operation of SRM drives, various results were demonstrated. The experimental tests proved that the new control scheme could successfully implement the speed control of the SRM under real operating conditions. It was found that the hybrid speed control algorithm is well suited to SRM drives. Apart from this, the merits and demerits of several control approaches are investigated to emphasize the features of the presented hybrid controller. The advantage of designing and implementing the hybrid controller requires a high speed DSP, few logic IC's and a single current sensor.

\section{REFERENCES}

1. Krishnan, R., 2001. Switched Reluctance Motor Drives: Modeling, Simulation, Analysis, Design and Applications. CRC Press. Hardcover ISBN: 0849308380

2. Miller, T.J.E., 1989. Brushless Permanent Magnet and Reluctance Motor Drives. Oxford University Press.

3. Lindsay, J.F., R. Arumugam and R. Krishnan, 1986. Finite-element analysis of a switched reluctance motor with multi-tooth per stator pole. Proc. Inst. Elect. Eng. B, 133: 347-353.

4. Byrne, J.V. and M.F. McMullion, 1982. Design of a reluctance motor as a $10 \mathrm{~kW}$ spindle drive. Motor con proceedings, pp: $10-24$
5. Bruce Powell, ---------. A Low Cost Efficient Motor Driver. Motornetics Corp., Santa Rose, California.

6. Rose Welburn, -------. Ultra High Torque motor system for Direct drive robotics. Motornetics Corp., Santa Rose, California

7. Ray, W.F., P.J. Lawrension, R.M. Davis, J.M. Stephension, N.N. Fulton and R.J. Bake, 1986. High performance SR Brushless Drives. IEEE Transactions on Industrial Applications, IA-22: 722-730.

8. Caio, A. Ferreira, Stephen R. Jones, William S. Heglund and William D. Jones, 1995. Detailed Design of a 30-Kw Switched Reluctance Starter/Generator System for a gas turbine engine application. IEEE Transaction on Industry applications, 31: 3 .

9. Chen Hao, Xie Guilen, -----. 80C31 Single chip Computer control of SRM for Locomotive in coal Mines. Chinal University of Mining and Technology, Xuzhoba 221008, China.

10. Krishnan, R. and A.S. Bharadwaj, -----. A Comparative study of various motor Drive Systems for Aircraft applications. Motion Control Systems Research Group, Bradley Department of Electrical Engineering, Blacksburg, at 24061-0111.

11. Moreira Julio C. and T.A. Lipo, 1989. Simulation of a four phase switched reluctance motor including the effects of mutual coupling. J. Electric Machines and Power Systems, 16:281-299.

12. Arkadan, A.A. and B.W. Kielgas, 1994. Switched reluctance motor drive systems dynamic performance prediction and experimental verification. IEEE Trans. On Energy conversion, 19: 36-44.

13. Panda, S.K. and P.K. Dash, 1996. Application of non-linear control of switched reluctance motors: a feedback approach. Proc. IEE EPA, 143: 371-379.

14. Buju, G.S., Menis Roberto and J. Valla Maria, 1993. Variable structure control of an SRM drive. IEEE Trans. On Industrial Electronics, 1: 56-63.

15. Silveri Bologani and Mauro Zigilotto, 1996. Fuzzy logic control of a switched reluctance motor drive. IEEE Trans. On Industry applications, 32: 10631068.

16. Syed, A. Hossain, Iqbal Husain, Harald Klode, Bruno Lequesne, Avoki M. Omekanda and Suresh Gopalakrishnan, 2003. Four-Quadrant and ZeroSpeed Sensorless Control of a Switched Reluctance Motor. IEEE Transactions on industry applications, 39: 5 . 
17. Lin, C. T. and C. S. Lee, 1996. Neural Fuzzy Systems. Englewood Cliffs, NJ: Prentice-Hall.

18. Ketata, R., D. De Geest and A. Titli, 1995. Fuzzy controller: Design, evaluation, parallel and hierarchical combination with a PID controller. Fuzzy Sets Syst., 71: 113-129.
19. Sayeed Mir, 2000. Classification of SRM Converter Topologies for Automotive Applications. SAE 2000, World Congress. Detroit, Michigan, March 6-9, 2000.

20. Anonymous, 2002. TMS320F2812 Datasheet, Texas Instruments. 